\title{
The Level of Job Satisfaction as Indicator of Work Value- Fulfillment Trend in Higher Education Systems
}

\author{
Chung Yeol Park ${ }^{1}$ and Ma. Hazel B. Ramos ${ }^{2}$ \\ ${ }^{1}$ International Business Management, Korea Nazarene University \\ ${ }^{2}$ International Business Management, Korea Nazarene University \\ ${ }^{1}$ cyp4x4@kornu.ac.kr, ${ }^{2}$ hbramos@kornu.ac.kr
}

\begin{abstract}
In the course of a working life in higher education institutions or HEIs, employees' set of work values namely security or promotion, pay, social or co-worker, supervision and growth (value-percept theory), are constantly changing. This study examined the level of job satisfaction that served as indicators of the trend of value-fulfillment in selected employees from different hierarchical commands crucial to organizational operations. Survey findings exhibited highest level of social and security satisfaction. While low pay and growth satisfaction were indicators that these values were not fulfilled by their jobs. However, the overall level of job satisfaction for all work values indicated by HEIs was comparatively higher than the standard norms of for-profit corporations. Thus, a reflection of a trend that employees' set of work values were provided by their jobs in HEIs, that led to high-performance organizations that place premium on higher education and in shaping minds and social orders.
\end{abstract}

Keywords: Job Satisfaction, Work Values, HEIs, Value-Fulfillment

\section{Introduction}

As organizations continue to face challenges including higher education institutions, both public and private sectors, job satisfaction of employees becomes essential in evaluating what they really value in their jobs. Job satisfaction is a pleasurable emotional state that results from the appraisal of one's job or job experiences (Colquitt, et.al. 2013). From the highest- ranking official down to the first-line managers and office staff, each one has different prioritized work set values that are perceived differently. The level of job satisfaction can be an indicator of the trend of their "wants" or what they really value in their current jobs, that directly affect their work attitudes, whether they are happy or unhappy performing their jobs.

The level of job satisfaction in a higher education institution or HEI shows high level in terms of job and contribution to profession. Faculty members and staff are more likely to engage in productive behavior as they are expected to be in the field of education molding young minds to better individuals in the society. When these employees attain high job satisfaction, there are visible things that their job provides the so-called "values" that they consciously or subconsciously want to seek. These work values are the basis of their sense of achievement that leads to increased work productivity and greater commitment. However, during the course of the employee's working life affected by various personal factors that come from cultural, political and economic environments, these work values or "wants" are constantly changing, too. Thus, it is vital to understand the trend of their work set values that are currently fulfilled by HEIs by evaluating the level of satisfaction, which is the core of this study.

Received (September 10, 2017), Review Result (January 15, 2018), Accepted (January 23, 2018) 


\section{Literature Research and Analytical Framework}

A. Role of Job Satisfaction. Job satisfaction causes job performance. There is a causal effect of job satisfaction on job performance posited as the oldest specification of the relationship that is often attributed to human relations movement (Judge, et.al. 2001). Hawthorne studies of Elton Mayo conducted in the 1920s began the investigation into whether workplace lighting level affected worker productivity where other work variables were altered such as wage levels, rest periods, and length of workday in later experiments (Kinicki/Williams 2013, p.47). Supported by G. Strauss (1968), he stated that "early human relationists viewed the morale-productivity relationship quite simply: higher morale would lead to improved productivity". While in the modern integrative model of organizational behavior, job satisfaction is one individual mechanism that directly affects job performance and organizational commitment (Colquitt, et.al. 2013). Job satisfaction helps increase retention rates and organizational commitment. Retaining talented and committed employees gives the organization an edge over competitors as they contribute more effectively than new hired employees (Ravine, 2016). According to Hesli and Lee, those who are working in top-ranked departments or private institutions tend to have higher levels of job satisfaction, which tend to be highest among professors. People who experience higher levels of job satisfaction tend to feel higher levels of affective commitment and higher levels of normative commitment (Colquitt, 2013). Job satisfaction increases company revenues. Cited in one article written in World Economic Forum, employee job satisfaction is positively associated with workplace financial performance, labour productivity, the quality of output and service, and an additive scale combining all three aspects of performance (Bryson, 2014).

B. Value-Percept Theory argues that employees will be satisfied when they perceive that their job offers the "five facets" relevant to judging their overall job satisfaction namely: pay, promotion, supervision, coworker and satisfaction with the work itself (Figure 1). Pay Satisfaction is an employee's feelings about their pay, whether they deserve it, secure and adequate for both normal expense and luxury items. Promotion Satisfaction is an employee's feelings about the company's promotion policies and execution, whether it's frequent, fair, and based on ability. Supervision Satisfaction is an employee's feelings about their boss, whether competent, polite and a good communicator. Coworker Satisfaction is an employee's feelings about their fellow employees, whether they are smart, responsible, helpful, fun, and interesting. Work Satisfaction is an employee's feelings about their actual work tasks, whether those are challenging, interesting, respected, and will make use of key skills. This theory can be summarized with the following equation:

$$
\text { Dissatisfaction }=(\text { Vwant }- \text { Vhave }) \times(\text { Vimportance }) \text {. }
$$

Vwant reflects how much of a value $n$ employee wants, Vhave indicates how much of that value the job supplies, and Vimportance reflects how important the value is to the employee. (Colquitt, 2013). The difference between wants and haves will reflect a sense of dissatisfaction, and when multiplied by importance will reflect existing discrepancies as to whether the figure is magnified for important values or minimized for insignificant values.

In Job Diagnostic Survey, these five facets were also used in assessing employee's attitudes about their jobs are: pay satisfaction, security satisfaction, social satisfaction, supervisory satisfaction, and growth satisfaction (Nelson, 2013), which will be used as a tool in conducting the study. 


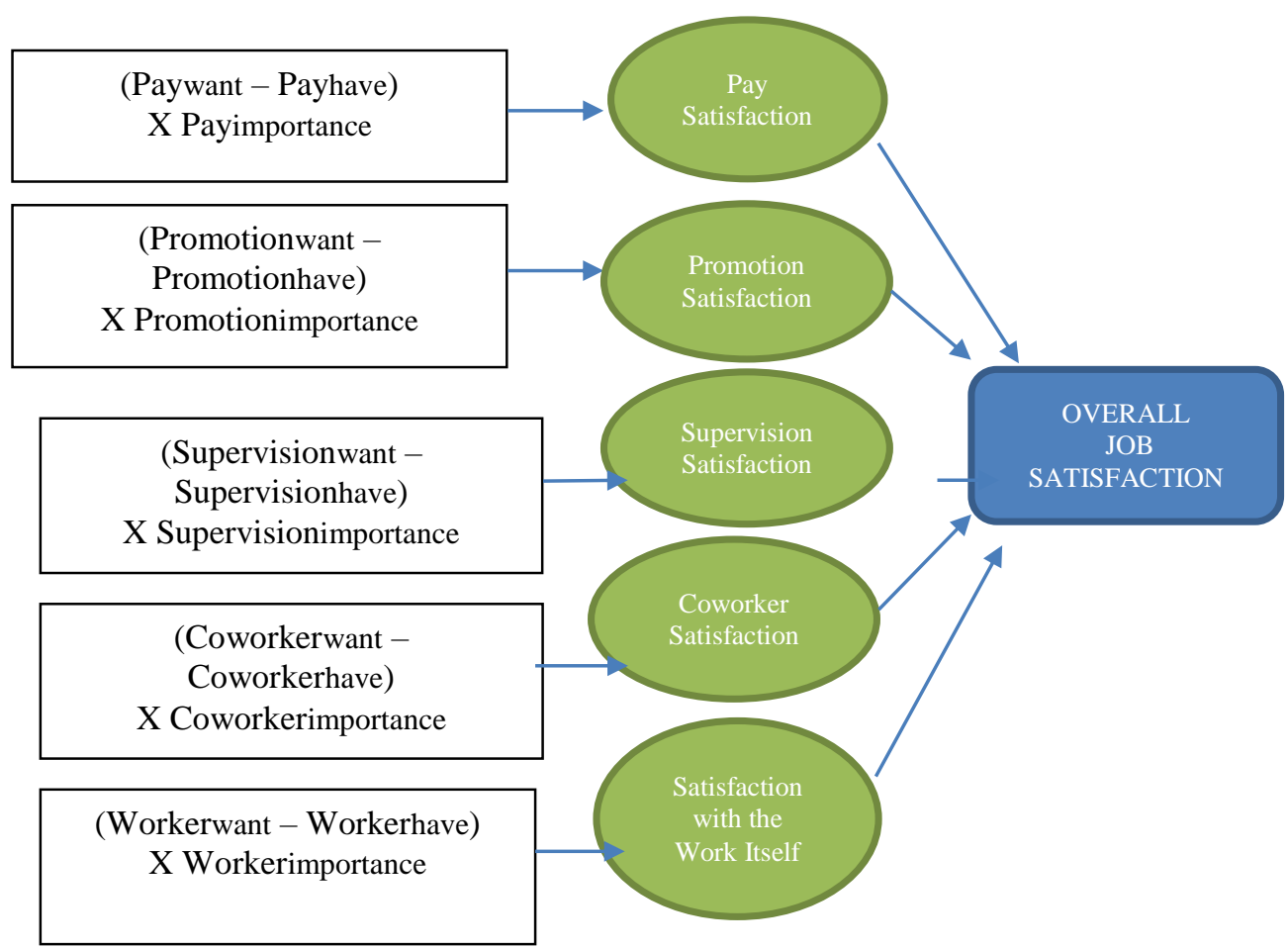

Figure 1. The Value-Percept Theory of Job Satisfaction

(Source: Colquitt/Le Pine/Wesson. Organizational Behavior. Improving Performance and Commitment in the Workplace. $4^{\text {th }}$ Ed. 2013.p.99-100)

C. The ABC Model of an Attitude argues that attitudes develop on the basis of evaluative responding to an entity (person, object, situation, or issue) on an affective, cognitive or behavioral basis. Affect is the emotional component of an attitude that can be measured by physiological indicators. Behavioral is the intention to behave in a certain way toward an object or person. Cognitive component reflects a person's thoughts, perceptions, or beliefs (Nelson, 2013). These three components can be used to evaluate employee's attitudes toward facets of job satisfaction. To thoroughly understand an attitude particularly at work is to assess all these three components. For example, you want to evaluate your employee's attitudes toward working with a diverse work pool in another location. You would want to determine how they feel about being assigned to work with diverse people and being relocated (affective), whether they would use this opportunity (behavioral intention), and what they think about the working conditions (cognition).

The ABC model helps in learning attitude formation towards work that lead to values formation creating either high or low level of job satisfaction.

\section{Research Method}

There was a purposeful and selective study population in selected seven (7) universities that were composed of Vice-president, dean, department chair, office manager and staff and their socio-demographic characteristics such as age, gender, employment status whether tenure or non-tenured, position played in the academic structure, and number of years worked in the organization were included as useful information that directly affect the work values they want to fulfill in their jobs. The widely used abbreviated version of Job Diagnostic survey with the list of fourteen questions was used as a standard tool distributed personally and via email, tested 
and predetermined to insure validity and reliability of the process and questions. To indicate how satisfied the respondents are with each aspect of the their job, there were seven scales used namely $1=$ Extremely dissatisfied, $2=$ Dissatisfied, $3=$ Slightly dissatisfied, $4=$ Neutral, $5=$ Slightly satisfied, $6=$ Satisfied, and $7=$ Extremely satisfied. The facets of job satisfaction covered by the questionnaires were pay, security, social, supervisory and growth (value-percept theory). To derive the results of each facet of job's level of satisfaction, the following formula was followed: $(Q 2=$ Question No. 2)

$$
\begin{aligned}
& \text { Pay Satisfaction = Q2 + Q9 / } 2 . \\
& \text { Security Satisfaction = Q1 + Q1 / } 2 . \\
& \text { Social Satisfaction = Q4 + Q7 + Q12 / } 3 . \\
& \text { Supervisory Satisfaction = Q5 + Q8 + Q14 / } 3 . \\
& \text { Growth Satisfaction = Q3+Q6+Q10+ Q13 / } 4 .
\end{aligned}
$$

The results derived were compared to the scores of set common norms for a large sample of managers for for-profit corporate industry: Pay Satisfaction -4.6, Security Satisfaction -5.2, Social Satisfaction-5.6, Supervisory Satisfaction- 5.2, and Growth Satisfaction- 5.3. The scores lower than four (4) suggests that there is room for change, given the scores on the facets that range from 1 to 7 (J. Richard Hackman and Greg R. Oldman, Work Redesign (Upper Saddle River, NJ: Pearson Education, Inc. 1980).

\section{Findings and Analysis}

\subsection{Socio-Demographics}

The selected potential study population in seven selected universities hold significant positions and rank related to operations, which was composed of two (2) Vice-Presidents, fourteen (14) Academic Deans, nineteen (19) Professors, and twenty-three (23) managers, and twelve (12) staff (shown in Figure 4.1.1). There were thirty-five (35) males and thirty-five (35) females with the following segmentation: University $A=7$ males and 3 females, University $B=3$ males and 7 females, University $\mathrm{C}=4$ males and 6 females, University $\mathrm{D}=5$ males and 6 females, University $\mathrm{E}=4$ males and 6 females, University $\mathrm{F}=5$ males and 5 females, and University $\mathrm{G}=7$ males and 3 females (Figure 4.1.2). For age distribution, five (5) were young employees ranging from 29-35 years old, 12 employees ranging from 36-40 year old, 8 employees ranging from 41-45 years old, and 45 employees ranging from 46 years old and above, comprising $64 \%$ of the total number of respondents (Figure 4.1.3). Most of the respondents have tenured status comprising fifty-three (53) employees and seventeen (17) have non-tenured status (shown in Figure 4.1.4). The longest tenured-employee is holding a post of deanship and have worked for thirty-eight years in the institution. On the other hand, a professor who has worked for one year was considered the youngest and new in the field. 


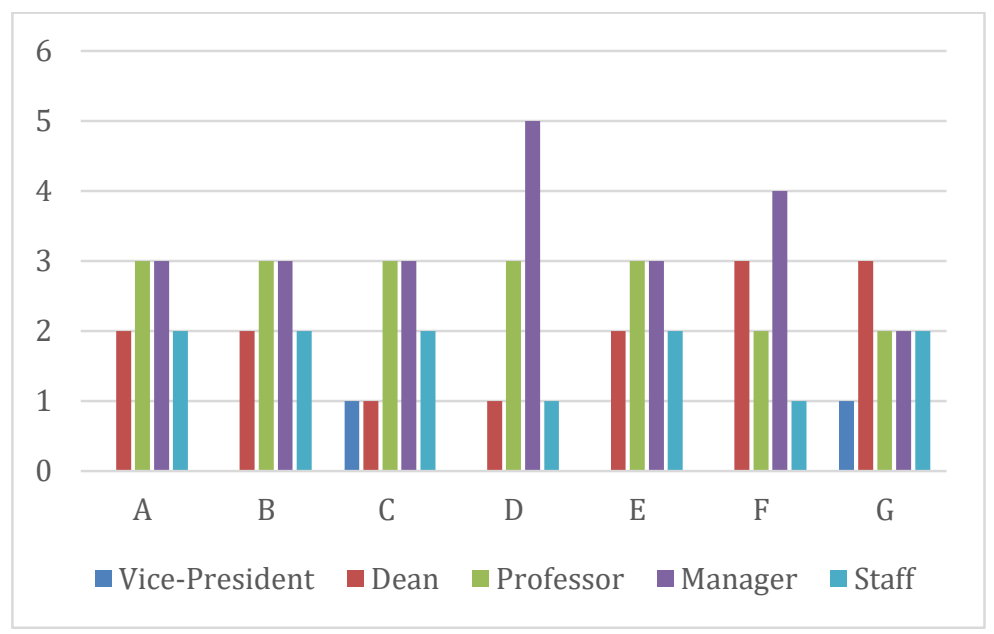

Figure 4.1.1. Position and Rank Segmentation

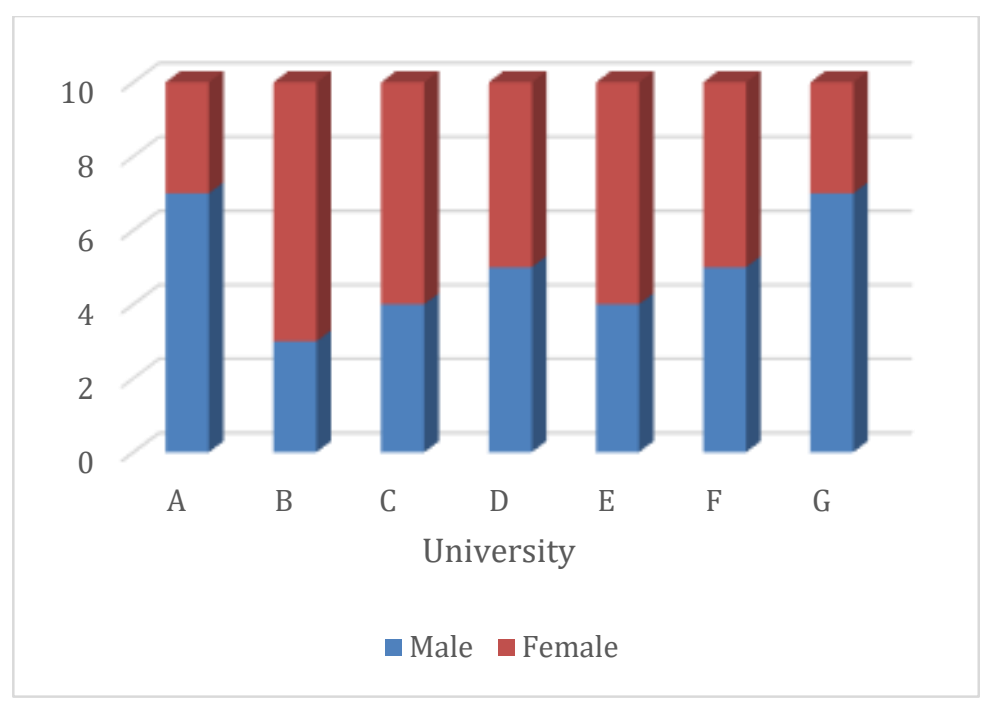

Figure 4.1.2. Gender Segmentation

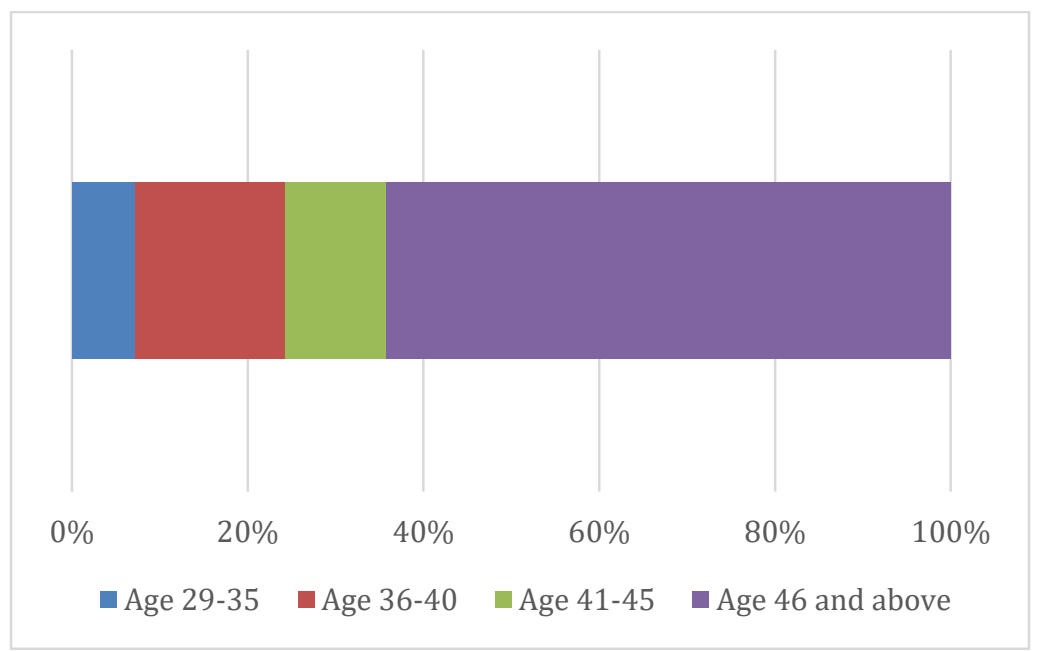

Figure 4.1.3. Age Distribution 


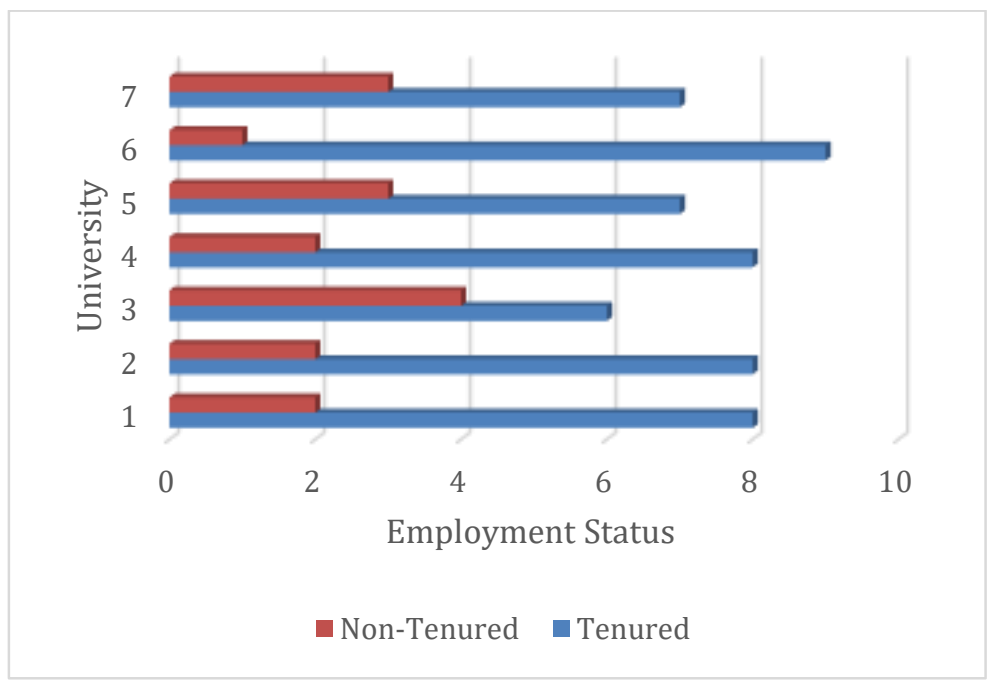

Figure 4.1.4. Employment Status Segmentation

Since HEIs have multicultural workforce, the set socio-demographic characteristics such as age, gender, position or rank in the organizational structure, employment status (tenured or non-tenured), and the number of years worked, helped assess the level of job satisfaction that indicated the importance and the trend pattern of values they prioritized and were fulfilled in their jobs. Results showed that aging workforce (46 and above) were more satisfied with the facets of their jobs and most of them value their job security. The higher the rank in the organization structure an employee holds and the longer the number of years he or she has worked positioned an employee in a tenured employment status, and were found to be more satisfied in all work values. This means the job has provided the employee wants and fulfilled their work values.

Also illustrated in the findings, that a Vice-president who worked for thirty-five years and a Dean who worked for thirty-eight years are most satisfied in all job facets, pay, security, social, supervision and growth. It is a clear indicator of their value-fulfillment, professional growth and contribution to the institution, as a whole.

Comparatively, a young staff with a 2-year working experience and a professor with a one-year working experience will be the least satisfied with their job pay and job growth because there is much more to discover and process their work attitudes. And in the course of their work, attitudes toward work are formed or sometimes can change their work set of values they seek in their jobs. For example, a tenured status employee who worked with a satisfactory job performance for 5-10 years will put premium on the job security than an employee who is just on his entry years who will put premium on work value such as pay and social. When these work values will be fulfilled, the happier the employee is and his evaluative response will create a good level of job satisfaction that leads to aspiring to long organizational commitment with better job performance. In addition, male employees and female employees vary on their values and evaluative responses to job facets as well. Male employees will value pay and security as the head of the family while female employees will value social and growth in their jobs.

\subsection{Level of Job Satisfaction Segmentation based on Job Facets}

In Figure 4.2.1, University A showed that most employees were most satisfied with the security in their jobs (5.9) and the least satisfied with the pay (4.8). University B employees were most satisfied with the social or co-workers (5.83) and 
least satisfied with job growth (4.9). University $\mathrm{C}$ employees were also most satisfied with the social or co-workers (5.61) and least satisfied with pay (4.8). University D employees were most satisfied with job security (5.4) and least satisfied with job growth (4.9). University E employees were most satisfied with social or co-workers (5.87) and least satisfied with pay. University F employees were most satisfied with job security (6.7) and least satisfied with growth (6.2). University $G$ employees were most satisfied with social or co-workers (6.3) and least satisfied with pay (5.35).

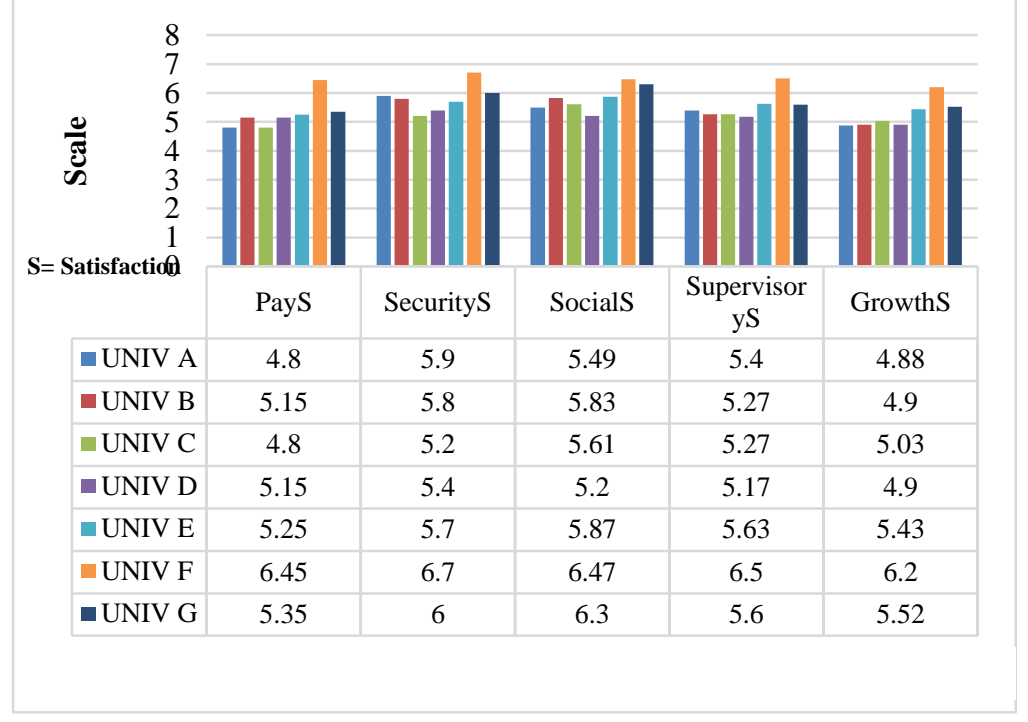

Figure 4.2.1. Job Satisfaction by University

The level of job satisfaction are indicators that HEIs have common trend that the work value of job security and social or co-workers were highly fulfilled while pay and growth that their jobs provide them still created a gap of dissatisfaction.

The level of job satisfaction by rank segmentation (Figure 4.2.2) shows that Deans were the most satisfied with job security (6.48) and least satisfied with job growth (6.09). They were expert of their crafts, thus creating less room for growth, thus low value-fulfillment in this work value. Professors were most satisfied with social or co-workers (5.59) and least satisfied with pay (4.79). Diversity in professors' pool provided a good social environment while the value of pay still has to be fulfilled according to their expectations. Deans and professors were the most tenured in terms of employment status that speaks of stability, having worked more than 20 years for the Deans and more than 10 years for the latter. As long as they perform at their best as lifeline or front liners for quality teaching and curriculum development, they are valued as assets to the institutions and will be guaranteed a tenured status of employment that means security of job. Diversity in the workplace in terms of expertise, age and experiences, is a significant driver for the fulfillment to social or co-workers want of deans and professors. They are able to build a good team or department maximizing the strength and uniqueness of each employee. A high level of satisfaction in growth is an indicator that professors' job provides them platforms for innovativeness and creativity for professional work.

Managers were most satisfied with job security (6.48) least satisfied with growth (5.52). Most of them were identified to have worked in the institutions for more than 20 years that also speaks of stability and tenured status of employment. Their jobs that were repetitive in nature, created them to be highly performing employees that led them to stability, however, too much familiarity of work leads to less room for 
innovation and growth. Staffs were most satisfied with social or co-worker (5.06) and least satisfied with pay (3.79). Though their jobs enabled them to establish good connections and work coordination, they remain to be support personnel and do not receive as much as the lifelines employees do. This is due to the nature of their employment status that is subject to renewal every two years. And staffs working with satisfactory job performance for 10 and more years will acquire tenured status.

Among the positions and the ranks, VP, the deans and managers have high valuefulfillment in their jobs as indicated by the level of their job satisfaction. They have proven their tracks, expertise, and are high performing individuals who have high level of familiarization with the complexity of systems and operations in institutions for longer period of time.

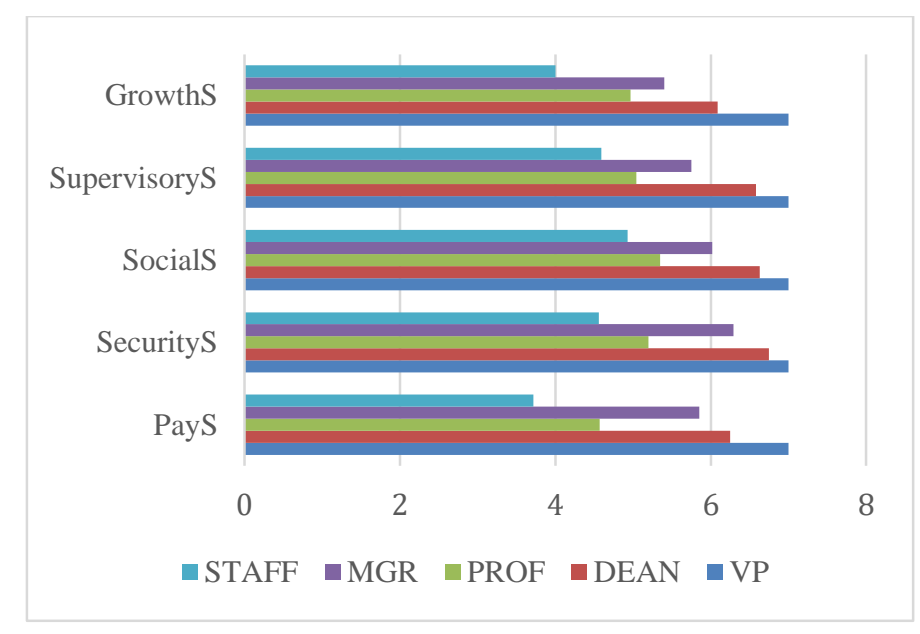

Figure 4.2.2. Job Satisfaction by Rank

By segmentation, the highest level of satisfaction for deans is security with 6.48 , followed by social with 6.48 , comes next is supervisory with 6.41 , pay is 6.18 and growth is the least satisfied work value with 5.89 level of satisfaction (Figure 4.2.3). The highest level of satisfaction for deans is an indicator that there is a high valuefulfillment of security provided by their jobs. They tend to be committed and stay longer in the institution as they continuously are inspired to deliver quality teaching and curriculum program for higher education to students. Good co-workers who support their vision and advocates to building a good team and department was also fulfilled as indicated to be the second highest level of satisfaction.

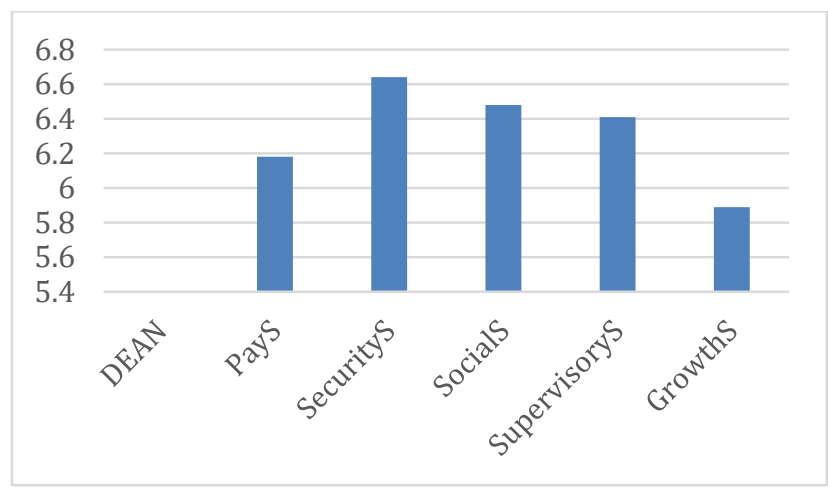

Figure 4.2.3. Job Satisfaction of Deans 
For professors, the highest level of satisfaction is social 5.59, followed by security with 5.42 level of satisfaction, supervisory with 5.26, growth with 4.83 and the least satisfied work value is pay with 4.79 level of satisfaction (Figure 4.2.4). Professors want good social or good co-workers to work with and this work value is fulfilled with the working environment of HEIs. This is due to the nature of the institution that provides diverse pool of professors being labeled as the lifeline of the institution operations. Maximizing the strength of a diverse pool of professors will make them happy, and perform at their best that lead to longer commitment to institution. The security they want in a job is fulfilled as indicated as the next highest level of satisfaction. In terms of stability, they remain to be steadfast not just in being tenured status but steadfast in the field of their expertise and contribution to the institutions as a whole.

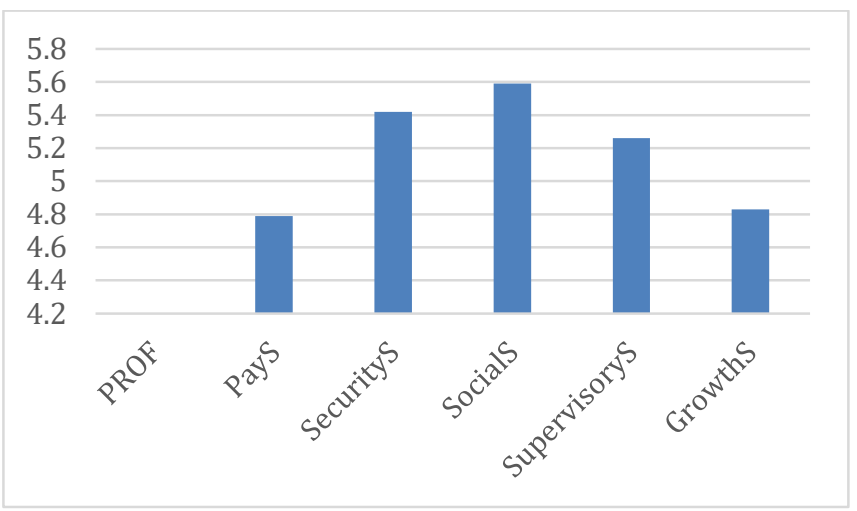

Figure 4.2.4. Job Satisfaction of Professors

For managers, the highest level of satisfaction is security with 6.48 , followed by social with 6.22 , comes next is pay with 6.07 , supervisory with 5.99 and the least satisfied is growth with 5.52 level of satisfaction (Figure. 4.2.5). They want security in their jobs and this value is fulfilled as indicated as highest level of satisfaction. They are engaged with administrative operations that are routine and repetitive in nature. This creates high level of familiarization, equipping to reduce errors at work that eventually mold them to be high performing employees. High performing employees are acknowledged, rewarded and valued allowing them to be stable in employment status due to high recommendation for contract renewal. Managers who reached tenured status will receive high value fulfillment of security and stability of work. However, the repetitive nature of their job will not fulfill their wants for growth that was indicated by lowest level of satisfaction. Being engaged with administrative functions for more than 10 years already, learning new things will be the least to expect. On the other hand, the growth that staffs are seeking that their job will be able to provide is highly fulfilled due to scope of work can be progressive enabling them to have much room for improvement and new learning. Moreover, their lower position in institution structure inspires them to be proactive in climbing their ladder of success that will lead them to opportunity creation towards greater learning in their crafts, processes, and systems. 


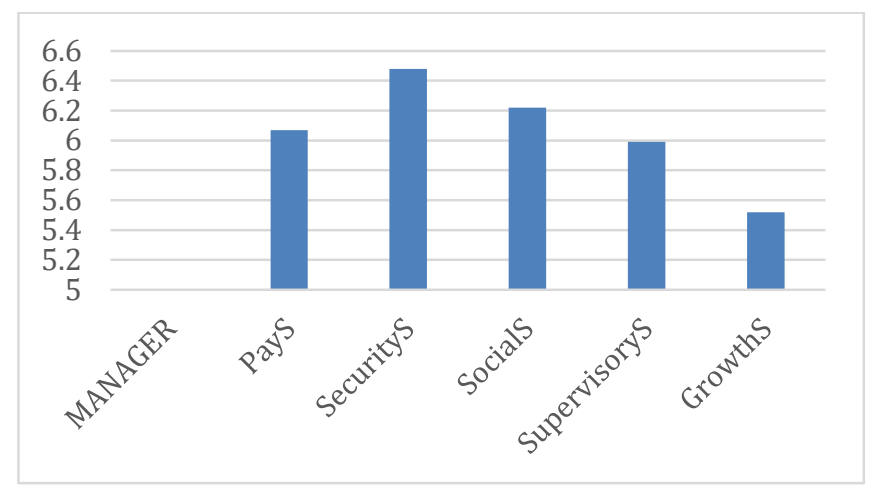

Figure 4.2.5. Job Satisfaction of Managers

Except for managers and deans, pay has the lowest value-fulfillment due to academic institutions put a premium on the image of 'giving rather than receiving' principle. Although it is a profit institution except for the public Academic Institution that is subsidized by government, the profit is not magnified due to corporate social responsibilities and other activities in the spirit of volunteerism ushered by the employees. Thus, instilled in the minds and hearts of employees that pay or money should not be the first value perceived for the job to provide.

For staffs, the highest level of satisfaction is social with 5.06, followed by security with 4 , comes next is supervisory with 4.53 , growth with 4.1 and the least satisfied work value is pay with 3.79 level of job satisfaction (Figure 4.2.6). Staffs in the offices want good co-workers, too that enable them to establish good connections and work coordination. This value is fulfilled in their jobs. However, their "want" in pay is not fulfilled. This is due to hierarchical scheme of pay structure implemented in the institution where office staff is seen to be the support personnel and do not receive as much as the employees considered as the lifeline in institutional structure.

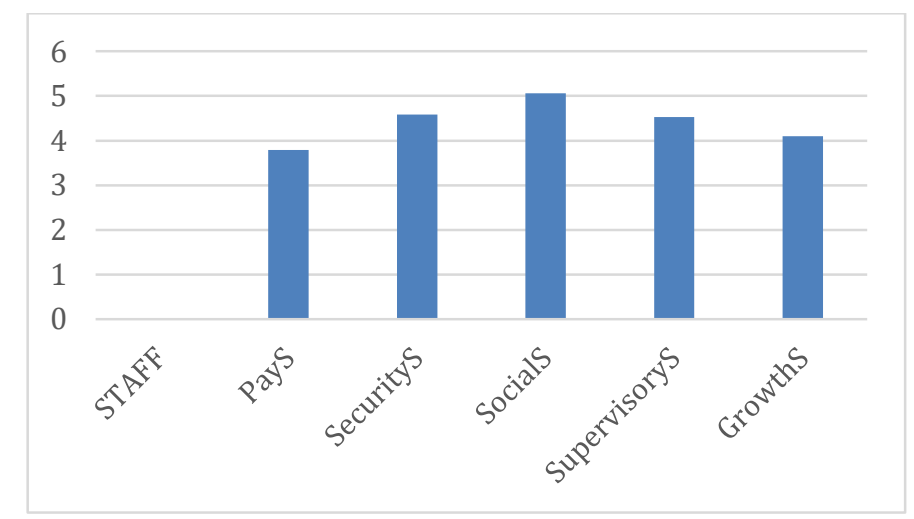

Figure 4.2.6. Job Satisfaction of Staffs

\subsection{Comparative Trend of Value Fulfillment between an Industry and Higher Education Institution (HEI)}

The results of level of job satisfaction of employees in selected higher education institutions were compared to the scores of abbreviated version of Job Diagnostic Survey which is said to be the common norms for a large sample managers in purely for-profit organizations or industry that focuses on profit-making only.

In comparison to the common norms of purely for-profit corporate industry, the HEI showed significant higher level of social (5.99) and security (5.6) satisfaction 
than 5.6 and 5.2 respectively as showed in Figure 4.3.1. Though both organizations have multicultural workforce that provide them avenues for social relationships and aids from co-workers, the level of satisfaction in higher education institution is higher than industry's. An indicator that HEIs is fulfilling social work set values in a better way. Also, both of the organizations' employees had the lowest pay satisfaction, however, the scale of 5.48 in HEIs is higher than of industry's scale level of 4.6. This is another indicator that HEI is providing a more satisfactory pay for a rendered service of an employee than those in the industries.

Growth satisfaction comes next as high level score of 5.3 for employees in industries while it is the second lowest level of satisfaction of 5.49 for employees in HEIs. This is because the nature of operations in industries that have wide range of resources and processes as compared to HEIs, processes are customary and less room for innovations. Highest level of security satisfaction of 5.96 in HEIs is higher than the common norms of 5.2. On the other hand, supervisory satisfaction level is 5.79, higher than the common norm, which is 5.2.

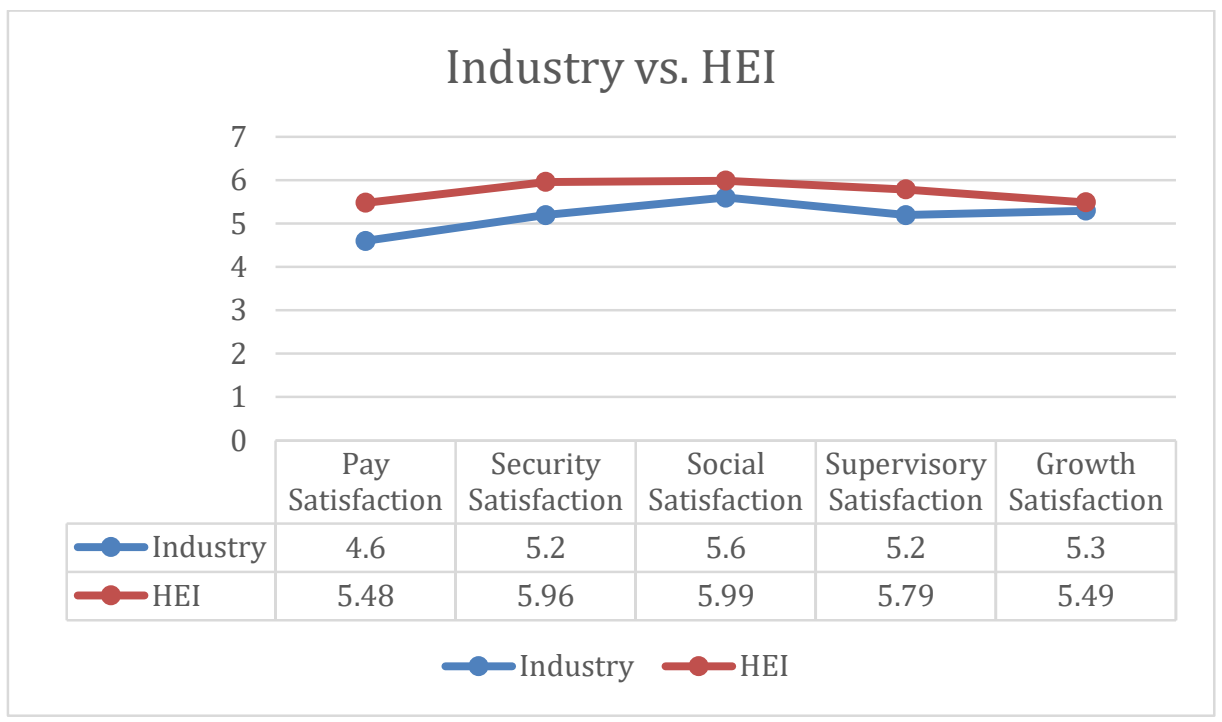

Figure 4.3.1. Comparative Trend of Value-Fulfillment: Industry vs. HEI

\section{Conclusion and Recommendations}

Job security, social, and growth are work values that HEIs employees constantly seek were fulfilled nowadays, as exhibited by a high level of satisfaction. They exhibited highest value-fulfillment in both social and security work values particularly to the aging workforce, in contrast with the younger office staffs' low level of fulfillment due to their renewable contract every two years. There was a high social value-fulfillment in both HEIs and corporate organizations while pay and growth had low level of fulfillment. This is an indicator that the work value an employee wants in their job which is to grow technically, conceptually and interpersonally is less fulfilled in both type of organizations. The low valuefulfillment of growth is an indicator that there is less room for growth in HEIs. The lowest pay satisfaction for managers, professors and staffs were in contrast for highrank and tenured employees such as VP and Deans having worked for more than twenty years. The lowest pay value-fulfillment is interpreted that an employee wants is not completely fulfilled with what the job is providing them, perhaps they are getting lower than what they want or not compensating with the demands and scope of tasks of their jobs. Either mid-high or mid-low level of supervisory satisfaction is exhibited by all ranks of employees. The level of pay satisfaction that is lowest for 
managers, professors and staffs but high for high-rank and tenured employees such as VP and Deans having worked for more than twenty years, is an indicator that the more you stay longer in the institutions, the more pay becomes a value fulfilled.

The level of satisfaction in pay, security, social, supervisory, which none was below the score of 4 in HEIs, remains significantly higher as compared to the common norms in an industry, thus, are not requiring room for change. However, there is always room for improvement to raise level of satisfaction of security, growth and pay work values. Here are some recommended actions for value fulfillment of employees in HEIs:

1. Growth - There is a need to create novel faculty development programs to engage deans and professors in new and active learning, innovation opportunities that help them not just to shape the minds of the young generation but create solutions that address global problems and issues. Allow them to engage in technical and professional development programs to break managers and staffs' repetitive work routines.

2. Pay - increase monetary rewards for additional employee benefits such as giving of an additional vacation day, or travel incentives or meal allowance, movie tickets and many others related to intrinsic rewards.

3. Security - minimize contractualization, conduct timely and thorough job performance appraisal especially to staffs to give access for promotions.

The job satisfaction level of employees in HEIs is an indicator of the current trend of value-fulfillment by the institution they chose to be committed to. The high level value-fulfillment of security and social, is a refection that HEIs have provided them stability and good workers which make the course of their working experience happier. Moreover, it enables them to highly perform tasks that increase organizational commitment for better work productivity. However, except for the managers and deans, pay is expected to have the lowest level of value-fulfillment due to the fact that even if higher education institutions are categorized as for-profit organization, the institution continues to put a premium on the image of "noble profession and vocation' principle. This means that a part of corporate values that shape the employees' attitude towards work is emphasizing service and making a difference and less of earning money. Social responsibilities and spirit of volunteerism is magnified, consequently, the value of pay is neglected or is not fulfilled in higher education institutions.

\section{Acknowledgments}

This paper is a revised and extended version of a paper entitled Job Satisfaction as Indicator of Trend in Value Fulfillment in Academic Institutions presented at The $9^{\text {th }}$ International on Future Generation Information Technology, Daejeon, Korea, on December 21-23, 2017.

\section{References}

[1] M. Biro, "Happy Employees = Hefty Profits", Forbes. Web, (2014).

[2] 'A. Bryson, "Do happy employees lead to higher profits?". Forum Agenda. Web, (2017).

[3] J. Colquitt, J. LePine and M. Wesson, Organizational Behavior", Improving Performance and Commitment in the Workplace. 4th Edition. McGraw-Hill Education. New York, (2013).

[4] V. Hesli and M. Lee, "The Profession. Job Satisfaction in Academia: Why are some faculty happier than others?”, Apsanet.com. Web, (2017).

[5] T. Judge, "The Job Satisfaction-Job Performance Relationship: A Qualitative and Quantitative Review", Pyschilogical Bulletin. Web, (2001).

[6] 'A. Kinicki and B. Williams, "Management”, A Practical Introduction. McGraw-Hill. New York, (2013).

[7] R. Mayhew, "Employee Retention and Satisfaction", Chonicles.com. Web, (2017). 
[8] Q. Nelson, "Principles of Organizational Behavior", Realities and Challenges, 8Th Edition. SouthWestern Cengage Learning, (2013).

[9] 'A. Ravine, "The Importance of Job Satisfaction", Everjobs.com. Web, (2016).

[10] T. Shinde, "International Multidisciplinary Research Journal", vol. 5, issue 11, ISSN No.2231-5063. Web, (2016).

[11] P. Skulason, "Nature and Purpose of Academic Thought". Web, (2006).

[12] C. Y. Park and M. H. Ramos, "Job Satisfaction as Indicator of Trend in Value Fulfillment in Academic Institutions", Proceedings of the $9^{\text {th }}$ International on Future Generation Information Technology, Daejeon, Korea, (2017).

\section{Authors}

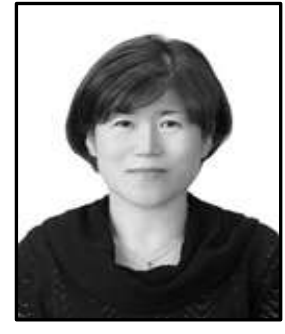

Park, Chung Yeol, her research interests are Language Education, Business Model, Business Management, International Business Management

-Feb. 1992: Sookmyung Women's Univ., English Literature, MS

- Dec. 2004: Oklahoma City Univ., TESOL, MS

- Dec. 2014: Hanyang Univ., International Business, MBA

- Feb. 1999: Sookmyung Women's Univ., English Literature, PhD

-Jan. 2007 Dec. 2008: California State Univ., Dept. of Education, Visiting Professor

-Aug. 2009 current: Korea Nazarene University., International Business management, Associate Professor

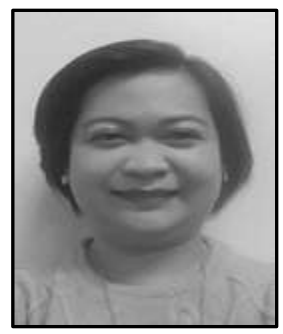

Ramos, Ma. Hazel B., her research interests are Human Resources and Organizational Behavior, Language Education, Tourism Dev't and Management, International Business Management

-Apr 2000: University of the Philippines, Linguistics, BA

- Apr 2009: UP School of Labor and Industrial Relations, DipIR (Post-diploma)

- Nov.2010: UP School of Labor and Industrial Relations, MIR

- Nov.2010-Jan 2014: Lyceum of the Philippines, Asst. to the Dean/Faculty Dev't Head

- Feb 2013-Mar 2014: Gyeongju University, Exchange Professor/ HR Head for International Professors

- Mar. 2014 current: Korea Nazarene University., International Business management, Asst. Professor 
International Journal of Advanced Science and Technology

Vol.112 (2018) 